\title{
Research On The Effect Of Heating On The Formability Of Titanium By Incremental Sheet Forming Technology
}

\author{
NGUYEN Tan Hung, LE Khanh Dien, NGUYEN Ngoc Phuong, NGUYEN Thanh Nam
}

\begin{abstract}
In the recent years, the application of Incremental Sheet Forming (ISF) in manufacturing small batch sheet products has increased rapidly, especially in medical treatment domain such as forming artificial titanium piece of human cranium because of the typical and unique cranium of each individual. This paper focus on the effect of heating on the formability of Titanium sheet material by ISF technology. Heating is one of the measures of increasing the formability of Titanium, the typical material that is permitted to manufacture the replaceable cranium. The design of experiment, the analyses of variance and the process are applied to the result of empirical process of circular lateral profile models in order to perform a regression equation that shows the relation of heat and other factors to the formability of Titanium sheet. The comparison
\end{abstract}

NGUYEN Tan Hung

CAO THANG Technical college

Vietnam

LE Khanh Dien

The Hochiminh City University of Technology, HCMUT,

Vietnam

LE Khanh Tan

Hochiminh City University of Technology Education, HCMUTE Vietnam

NGUYENNgoc Phuong

Hochiminh City University of Technology Education, HCMUTE Vietnam

\section{NGUYEN Thanh Nam}

Digital Control and System Engineering Laboratory, DCSElab, Vietnam of the result of models manufactured in ambient temperature and in heating is also mentioned to show the effect of heating sheet in ISF technology.

Keywords: ISF, heating, formability metal sheet, design of experiment, analyses of variance, regression equation, mechnical engineering.

\section{Introduction}

SPIF (Single Point Incremental Forming) and TPIF (Two Point Incremental Forming) are 2 methods of ISF technology (Incremental Sheet Forming), a new dieless forming sheet technology that was recommended by $\mathrm{E}$. Leszak in 1967 [1]. Figure 1 [2] shows the differences between SPIF and TPIF. From 1997 to now on, this forming sheet technology has been developed and has definitively great results in industry [3] .However; this forming sheet technology could not be applied in industry in the early years because of the weakness of the control technology of this time. In the beginning of the current century, this method has been developed rapidly and has definitive great results in industry in advanced countries... Unfortunately elasto-plastic and the limited plasticity is an inborn property of almost all materials that restrict the formability of the sheet material and caused lots of waste sheet product reduces the accuracy of the dimensions and of the shapes of the products. This paper concentrates to the effect of heating on the formability of sheet material especially Titanium because this material has had a lot of application in aeronautics and medicine especially in orthopedics. According to [4], we know that Titanium is a precious metal, in this paper we use pure Titanium grade 3 in our experiments 
Proc. of The Fifth Intl. Conf. On Advances in Mechanical, Aeronautical and Production Techniques - MAPT 2016

Copyright (C) Institute of Research Engineers and Doctors, USA .All rights reserved.

ISBN: 978-1-63248-090-3 doi: 10.15224/ 978-1-63248-090-3-42
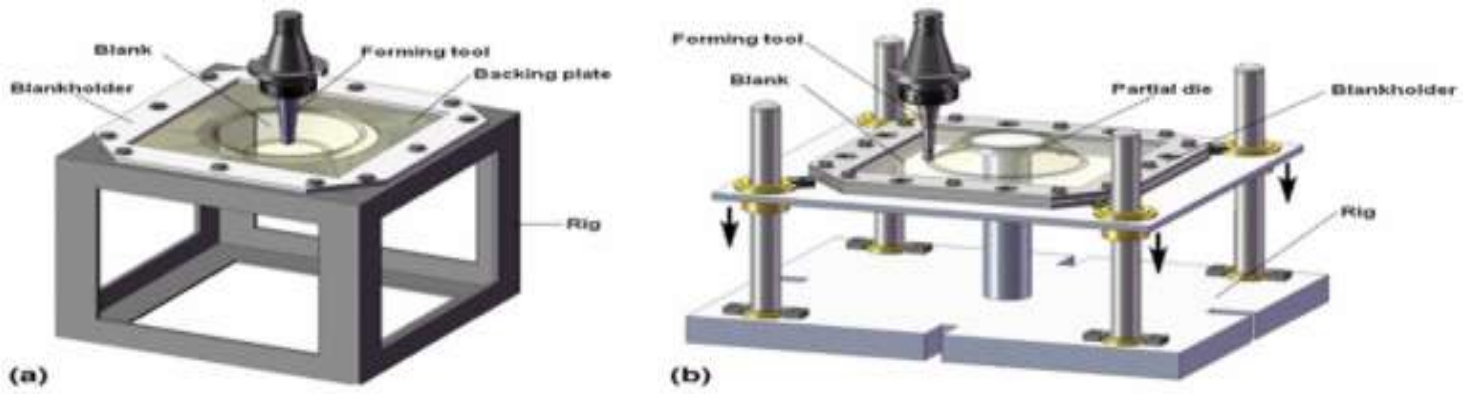

Figure 1: (a) Single Point Incremental Forming (SPIF)

(b) Two Point Incremental Forming (TPIF) [2]

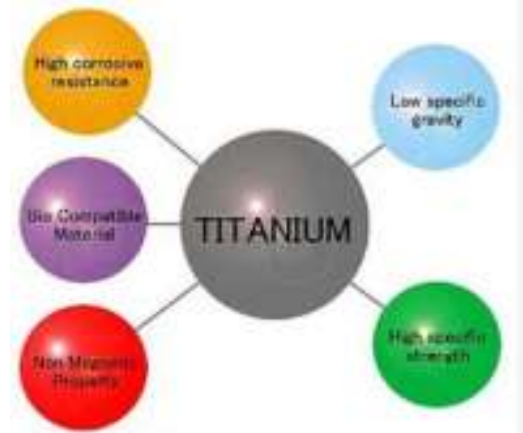

Figure 2: Good properties of Titanium

\section{Design of Experiment on the Effect of Heating on the Formability of Pure Titanium Sheet Grade 3}

\section{A. Experimental model}

In almost all SPIF experiment, the circular cone model (in figure 3) is selected because it could allow defining the deformation angle $\alpha$ at the depth $\mathrm{z}$ by the formula $\alpha=\arccos \left(\frac{x}{R}\right)$

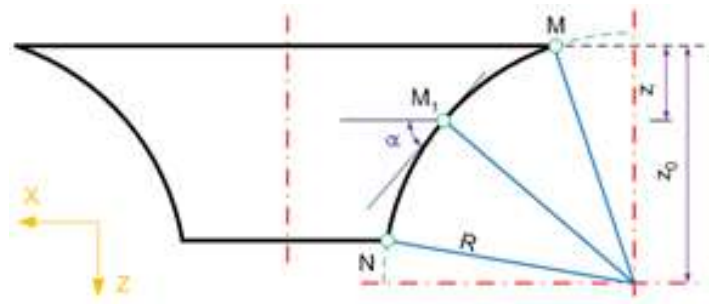

Figure 3: Model of Pure Titanium grade 3 in SPIF experiment.

\section{B. Experimental SPIF machine}

All the experiments are performed under the support of National key Laboratory of Digital Control and System Engineering laboratory (DCSELAB), Hochiminh City. Figure 4 displays the SPIF machine in CAD-CAM workshop of DCSELAB

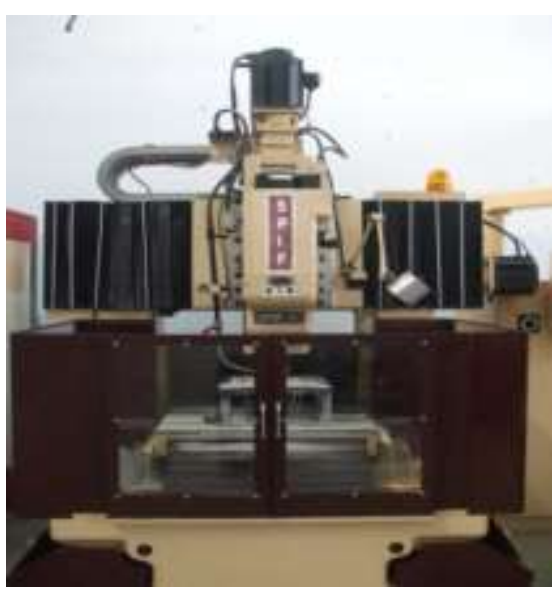

Figure 4: SPIF machine and feature in forming Titanium sheet, selected sheet thickness is $1 \mathrm{~mm}$

\section{Parameters in Design of Experiment (DOE)}

In order to study the effect of heating on the formability (angle $\alpha$ ) of pure Titanium grade 3 sheet, we select One-Haft Fraction of the $2^{k}$ Design [5] in 
Proc. of The Fifth Intl. Conf. On Advances in Mechanical, Aeronautical and Production Techniques - MAPT 2016 Copyright (C) Institute of Research Engineers and Doctors, USA .All rights reserved.

ISBN: 978-1-63248-090-3 doi: 10.15224/ 978-1-63248-090-3-42

which $\mathrm{k}=4$ : 4selected independent SPIF parameters: D (mm): Diameter of spherical tool tip,

$(\mathrm{mm})$ : Vertical feed after each perimeter orbit, Vxy $(\mathrm{mm} / \mathrm{min})$ : Horizontal circumference of tool velocity $\mathrm{T}\left({ }^{0} \mathrm{C}\right)$ : Temperature of pure Titanium sheet in SPIF forming. The temperature $\mathrm{T}$ is selected for the replacement of the mutual effect of 3 first parameters (D, $\Delta \mathrm{z}, \mathrm{Vxy})$ in One-Haft Fraction of the $2^{\mathrm{k}}$ Design.

\section{Initial value of SPIF parameters by DOE}

These limited values are selected due to the ability of SPIF machine, Titanium sheet, pestle tool, heating system and feature.

TABLE 1: SPIF LIMITED VALUE PARAMETER

\begin{tabular}{|l|l|l|l|l|l|}
\hline & \multicolumn{4}{|l|}{ Input parameter value } & $\begin{array}{l}\text { Studied } \\
\text { value }\end{array}$ \\
\hline $\begin{array}{l}\text { Rate } \\
\text { value }\end{array}$ & $\begin{array}{l}\mathrm{D} \\
(\mathrm{mm})\end{array}$ & $\begin{array}{l}\Delta \mathrm{z} \\
(\mathrm{mm})\end{array}$ & $\begin{array}{l}\text { Vxy } \\
(\mathrm{mm} / \mathrm{min})\end{array}$ & $\begin{array}{l}\mathrm{T} \\
\left.{ }^{(} \mathrm{C}\right)\end{array}$ & $\alpha\left(^{\circ}\right)$ \\
\hline Min & 6 & 0,3 & 500 & 30 & \\
\hline Max & 12 & 0,6 & 1500 & 600 & \\
\hline
\end{tabular}

For the convenience of computing in DOE we could use encoding method. The variable x1, x2, x3, x4 are successively encoded to $\mathrm{D}, \Delta \mathrm{z}, \mathrm{Vxy}$ and $\mathrm{T}$ : Average rate $\mathrm{X} 0=(\mathrm{X} \max +\mathrm{Xmin}) / 2$

Distance value $\quad \Delta \mathrm{X}=\mathrm{X} \max -\mathrm{X} 0=\mathrm{X} 0-\mathrm{X} \min$

TABLE 2: SPIF DOE PARAMETER VALUE

\begin{tabular}{|l|l|l|l|l|}
\hline & $\begin{array}{l}\mathbf{D} \\
(\mathbf{m m})\end{array}$ & $\begin{array}{l}\Delta_{\mathbf{z}} \\
(\mathbf{m m})\end{array}$ & $\begin{array}{l}\mathbf{V}_{\mathbf{x y}} \\
(\mathbf{m m} / \mathbf{m i n})\end{array}$ & $\begin{array}{l}\mathbf{T} \\
\left({ }^{\mathbf{}} \mathbf{C}\right)\end{array}$ \\
\hline $\mathbf{X i}$ & 9 & 0,45 & 1000 & 315 \\
\hline$\Delta \mathbf{X i}$ & 3 & 0,15 & 500 & 285 \\
\hline
\end{tabular}

Encoded parameter $\mathrm{xi}=(\Delta \mathrm{z}-\mathrm{Xi}) / \Delta \mathrm{Xi}$

$\mathrm{x} 1=(\mathrm{D}-9) / 3$

$\mathrm{x} 2=(\Delta \mathrm{z}-0,45) / 0,15$

$\mathrm{x} 3=(\mathrm{Vxy}-1000) / 500$

$\mathrm{x} 4=(\mathrm{T}-315) / 285$
In One-Haft Fraction of the $2^{\mathrm{k}}$ Design of Experiment with $\mathrm{k}=4$, the number of models is $2^{\mathrm{k}-1}=8$. Table 3 displays the initial value of 4 independent parameters

TABLE 3: THE INITIAL VALUES OF 4 INDEPENDENT PARAMETERS

\begin{tabular}{|l|l|l|l|l|l|}
\hline N0 & $\Delta_{\mathrm{z}}(\mathrm{mm})$ & $\begin{array}{l}\mathrm{V}_{\mathrm{xy}} \\
(\mathrm{mm} / \mathrm{ph})\end{array}$ & $\begin{array}{l}\mathrm{D} \\
(\mathrm{mm})\end{array}$ & $\mathrm{T}\left({ }^{\circ} \mathrm{C}\right)$ & $\begin{array}{l}\alpha \\
\left({ }^{\circ}\right)\end{array}$ \\
\hline 1 & 0,3 & 500 & 6 & 30 & \\
\hline 2 & 0,6 & 500 & 6 & 30 & \\
\hline 3 & 0,3 & 1500 & 6 & 30 & \\
\hline 4 & 0,6 & 1500 & 6 & 30 & \\
\hline 5 & 0,3 & 500 & 12 & 600 & \\
\hline 6 & 0,6 & 500 & 12 & 600 & \\
\hline 7 & 0,3 & 1500 & 12 & 600 & \\
\hline 8 & 0,6 & 1500 & 12 & 600 & \\
\hline
\end{tabular}

TABLE 4: ENCODING INPUT PARAMETER OF SPIF

\begin{tabular}{|l|l|l|l|l|l|}
\hline $\mathrm{N} 0$ & $\mathrm{x} 1$ & $\mathrm{x} 2$ & $\mathrm{x} 3$ & $\mathrm{x} 4=\mathrm{x} 1 . \mathrm{x} 2 . \mathrm{x} 3$ & $\alpha\left(^{\circ}\right)$ \\
\hline 1 & -1 & -1 & -1 & -1 & \\
\hline 2 & 1 & -1 & -1 & 1 & \\
\hline 3 & -1 & 1 & -1 & 1 & \\
\hline 4 & 1 & 1 & -1 & -1 & \\
\hline 5 & -1 & -1 & 1 & 1 & \\
\hline 6 & 1 & -1 & 1 & -1 & \\
\hline 7 & -1 & 1 & 1 & -1 & \\
\hline 8 & 1 & 1 & 1 & 1 & \\
\hline
\end{tabular}

The parameter $\mathrm{x} 4$ stands for heating temperature $\mathrm{T}$ is selected as the multiplication of the 3 remained parameters that represents the most robust mutual influence to the result parameter $\alpha$. The selected number of replication is 3 so the total number of experiment is $8 \times 3=24$.

\section{Empirical Experiment}

The figures below show all the empirical experiment to research the effect of heating on the ability of forming Titanium models in Cad-Cam Workshop of DCSElab 
Proc. of The Fifth Intl. Conf. On Advances in Mechanical, Aeronautical and Production Techniques - MAPT 2016

Copyright (c) Institute of Research Engineers and Doctors, USA .All rights reserved.

ISBN: 978-1-63248-090-3 doi: 10.15224/ 978-1-63248-090-3-42

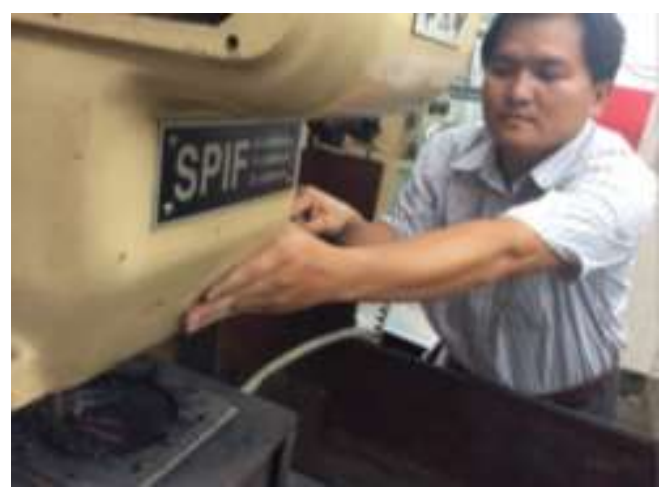

Figure 5: Preparation of installation in SPIF machine

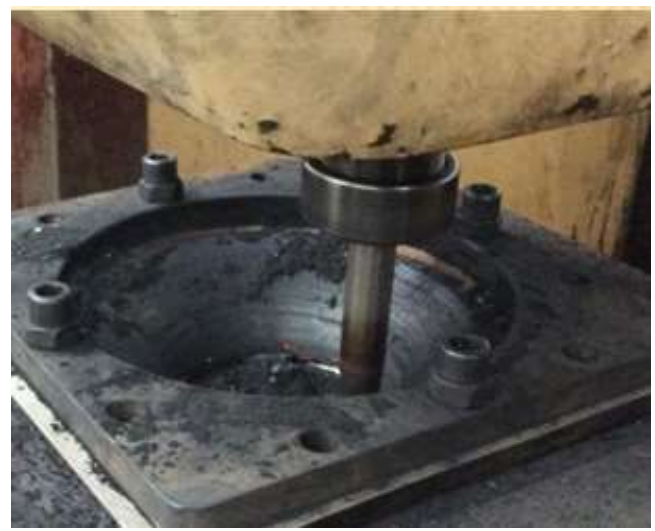

Figure 6: Forming Titanium model sheet by SPIF technology at $600^{\circ} \mathrm{C}$ with graphic powder lubrication

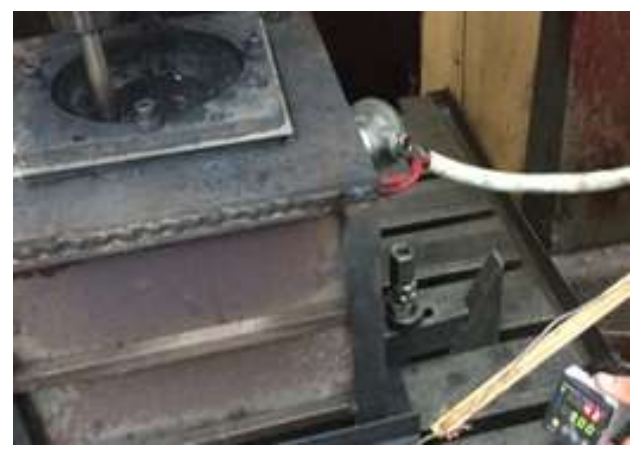

Figure 7: Heating system under SPIF feature 3

\section{Treating the Empirical}

\section{Experiment result by Minitab}

\section{Software}

The empirical experiment result of 24 runs is displays in the following table:
TABLE 5: RESULT OF EMPIRICAL EXPERIMENT OF 24 TITANIUM SHEET MODELS

\begin{tabular}{|l|l|l|l|l|l|l|l|}
\hline $\begin{array}{l}\mathrm{N} \\
0\end{array}$ & $\mathrm{x} 1$ & $\mathrm{x} 2$ & $\mathrm{x} 3$ & $\mathrm{x} 4$ & $\alpha 1\left(^{\circ}\right)$ & $\alpha 2\left(^{\circ}\right)$ & $\alpha 2\left(^{\circ}\right)$ \\
\hline 1 & -1 & -1 & -1 & -1 & 69 & 68,58 & 68,78 \\
\hline 2 & 1 & -1 & -1 & 1 & 71,98 & 72,26 & 72 \\
\hline 3 & -1 & 1 & -1 & 1 & 71,45 & 71,15 & 71,26 \\
\hline 4 & 1 & 1 & -1 & -1 & 67,25 & 67,68 & 67 \\
\hline 5 & -1 & -1 & 1 & 1 & 71,32 & 71,56 & 71,12 \\
\hline 6 & 1 & -1 & 1 & -1 & 68,28 & 68,14 & 68,45 \\
\hline 7 & -1 & 1 & 1 & -1 & 69,15 & 68,92 & 69,25 \\
\hline 8 & 1 & 1 & 1 & 1 & 71,22 & 71,12 & 71,06 \\
\hline
\end{tabular}

In order to treat the result of DOE we could calculate or apply a design of experiment software. Herein we use Minitab [6], popular software in DOE with the successive sessions that are displayed in the following figures:

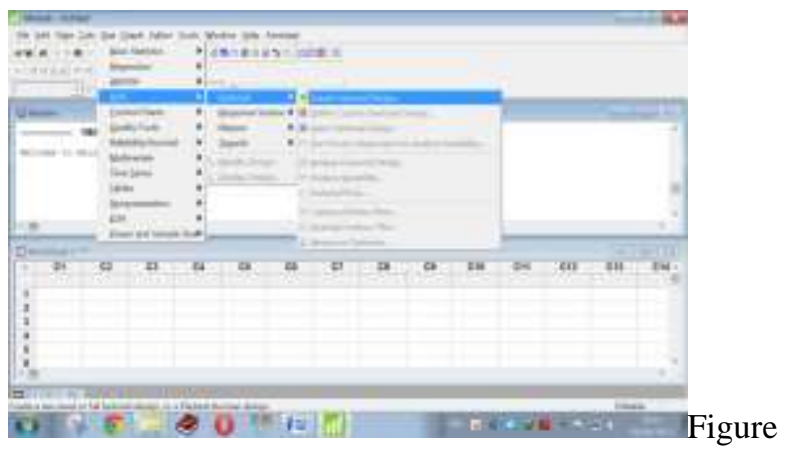

8: Minitab menu STAT/DOE/Factorial/Create factorial

Design is selected

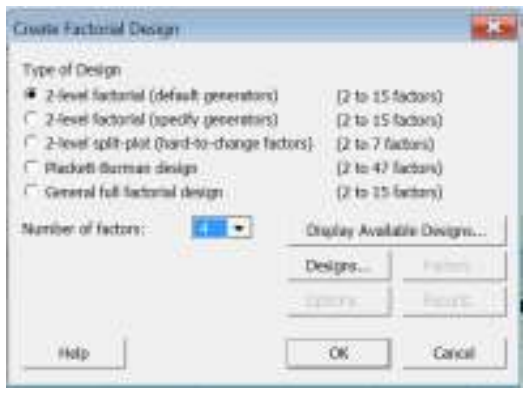

Figure 9: Create Factorial Design, 2-level, 4 factors 
Proc. of The Fifth Intl. Conf. On Advances in Mechanical, Aeronautical and Production Techniques - MAPT 2016

Copyright $($ Institute of Research Engineers and Doctors, USA .All rights reserved.

ISBN: 978-1-63248-090-3 doi: 10.15224/ 978-1-63248-090-3-42

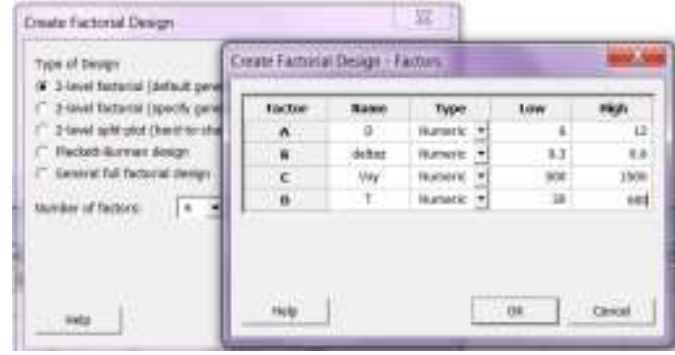

Figure 10 Create factorial Design with limited values The Session screen displays the following result:

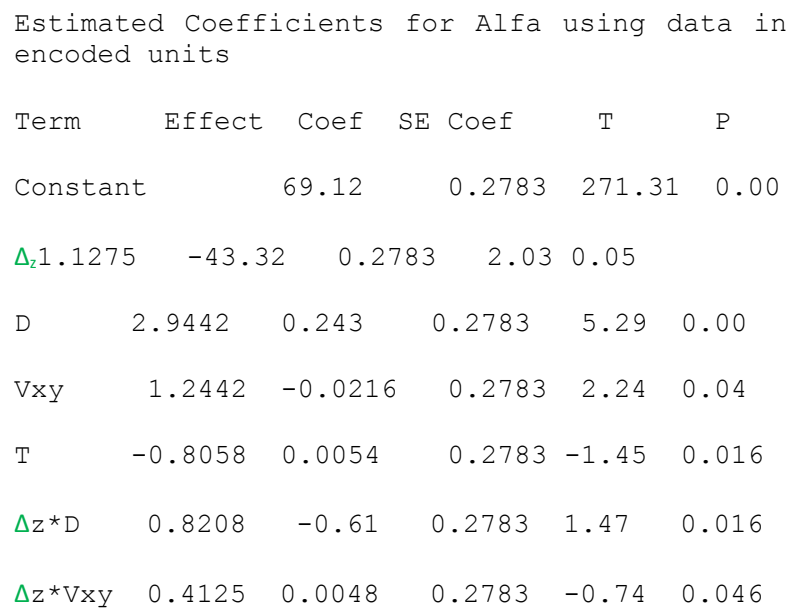

We consider that all $\mathrm{P}$ value are smaller or equal 0.05 so the result of $\mathrm{DOE}$ is reliable. The regression equation is formed by the extraction of the above coefficient values:

$\alpha=69,12+0,243 D-43,32 \Delta_{z}-0,0216 V_{x y}+0,0054 T-$ 0,61 D. $\Delta_{z}+0,048 \Delta_{z} \cdot V_{x y}(2)$

Comments:

- The formability of Titanium sheet (angle $\alpha$ ) increases in the diameter $\mathrm{D}$ and heating temperature Tether formability is inverse to $\Delta \mathrm{z}$ and Vxy

- To ameliorate the formability of Titanium sheet we could increase independently the Temperature of the sheet. However the high temperature of the formed sheet could influences also to the properties of the tool and the feature and other miniature electronic instruments,

\section{Result}

With Design of Experiment, the paper proposed a suitable measure of empirical experiment to determine the good effect of heating temperature via the regression equation that determines the good influence of the heating temperature in SPIF technology.

\section{Acknowledgement}

We appreciate highly the great support of National Key Laboratory of Digital Control and System Engineering (DCSELAB), VNU, HochiminhCity.

\section{References}

\begin{abstract}
[1] Edward Leszak"Apparatus and Process for Incremental Dieless Forming" Patent US3342051,Ser.No. 388.57710 Claims (Cl. 7281)[2] M.B. Silva and P.A.F. Martins "Two-Point Incremental Forming with Partial Die: Theory and Experimentation", @ASM International, DOI: 10.1007/s11665-012-0400-3, JMEPEG (2013)[3] Mladomir Milutinovica, Robert Lenđela Michal Potranb, Dragiša Vilotića,Plavka Skakuna, Miroslav Plančaka "Application of single point incremental forming for manufacturing of denture base", Journal for Technology of Plasticity, Vol. 39 (2014), Number 2

[4]H. K. D. H. Bhadeshia “Titanium \& its Alloys” Materials Science \& Metallurgy Part II Course C9, Alloys.[5] Douglas C. Montgomery "Design and analysis of Experiments" $7^{\text {th }}$ edition, John Wiley \& Son ISBN 978-0-470-12866-4, 2009[6] Minitab 17, ( 2014 by Minitab Inc.
\end{abstract}

About Author (s):

\begin{tabular}{|l|l|}
\hline NGUYEN Tan Hung B.E. (2006), M.E \\
(2009) in Mechanical Engineering from \\
Hochiminh City University of Technology \\
Engineering education, Head of CAD- \\
CAM Workshop, DCSElab, HCMUT, \\
VNU- HCM \\
Doctoral student in Single Point \\
Incremental Forming technology since \\
2013
\end{tabular}

\begin{tabular}{|l|l|}
\hline & $\begin{array}{l}\text { LE Khanh Dien, Engineer of Mechanical } \\
\text { Engineering (1982), Master of Mechanical } \\
\text { Engineering (1997), Lecturer of Faculty of } \\
\text { Mechanical Engineering of HCM City } \\
\text { University of Technology (HCMUT), } \\
\text { Doctoral Student since 2008 }\end{array}$ \\
\hline
\end{tabular}

